\title{
Effect of non-invasive mechanical ventilation on sleep and nocturnal ventilation in patients with chronic respiratory failure
}

\author{
Bernd Schönhofer, Dieter Köhler
}

\begin{abstract}
Background-Chronic respiratory failure (CRF) is associated with nocturnal hypoventilation. Due to the interaction of sleep and breathing, sleep quality is reduced during nocturnal hypoventilation. Noninvasive mechanical ventilation (NMV), usually performed overnight, relieves symptoms of hypoventilation and improves daytime blood gas tensions in patients with CRF. The time course of the long term effect of NMV on sleep and breathing during both spontaneous ventilation (withdrawing the intervention) and NMV was investigated in patients with CRF due to thoracic restriction.

Methods-Fifteen consecutive patients (13 women) of mean (SD) age $57.9(12.0)$ years with CRF due to thoracic restriction were included in the study. During the one year observation period four polysomnographic studies were performed: three during spontaneous breathing without NMV - before initiation of NMV (T0) and after withdrawing NMV for one night at six months (T6) and 12 months (T12-)and the fourth during NMV after 12 months (T12+). Daytime blood gas tensions and lung function were also measured.
\end{abstract}

Results-Spontaneous ventilation (in terms of mean oxygen saturation) progressively improved (from T0 to T12-) during both REM sleep $(24.8 \%, 95 \%$ CI 12.9 to 36.9$)$ and NREM sleep (21.5\%, $95 \%$ CI 12.4 to 30.6 ). Sleep quality during spontaneous ventilation also improved in terms of increased total sleep time $\mathbf{( 2 6 . 8 \%}$, 95\% CI 11.6 to 42.0 ) and sleep efficiency $(17.5 \%, 95 \%$ CI 5.4 to 29.6$)$ and decreased awakenings $(54.0 \%, 95 \%$ CI 70.3 to 37.7$)$. Accordingly, REM and NREM sleep stages 3 and 4 significantly improved. However, the most significant improvements in both nocturnal ventilation and sleep quality were seen during NMV at 12 months.

Conclusions-After long term NMV both spontaneous ventilation during sleep and sleep quality in patients with CRF due to thoracic restriction showed evidence of progressive improvement compared with baseline after withdrawal of NMV for a single night at six and 12 months. However, the greatest improvements in nocturnal ventilation and sleep were achieved during NMV at 12 months.

(Thorax 2000;55:308-313)
Keywords: chronic respiratory failure; mechanical ventilation; sleep; nocturnal ventilation

Chronic respiratory failure $(\mathrm{CRF})$ is associated with nocturnal hypoventilation and a reduction in sleep quality. ${ }^{1}$ Non-invasive mechanical ventilation (NMV), usually performed overnight, relieves the symptoms of hypoventilation and improves daytime blood gas tensions in patients with CRF..$^{2-6}$ The purpose of this study was to determine the benefit of long term NMV with respect to sleep quality and breathing, both during withdrawal and application of NMV, in patients with CRF due to restrictive chest wall disorders. We performed a prospective study to evaluate the hypothesis that, after a withdrawal period of one night, there is progressive improvement in sleep quality and spontaneous breathing during sleep six and 12 months after initiation of the NMV.

\section{Methods}

PATIENTS

The protocol was approved by our ethical review committee and written informed consent was obtained from all participants. The inclusion criteria were stable chronic hypercapnic respiratory failure $\left(\mathrm{PCO}_{2}>6.0 \mathrm{kPa}\right.$ and $<8.7 \mathrm{kPa}$ ) due to restrictive thoracic diseases (post-tuberculosis sequelae and idiopathic scoliosis).

In all patients there was no significant difference between two blood gas measurements taken one week apart, immediately before admission to hospital, indicating that the CRF was stable. Furthermore, an increased bicarbonate level represented a partially or completely compensated respiratory acidosis. The criterion for the introduction of NMV in these patients was the development of symptoms of nocturnal hypoventilation such as reduced mobility, increased dyspnoea during exercise, daytime sleepiness, or headache.

Exclusion criteria were sleep apnoea, obesity hypoventilation syndrome, chronic obstructive pulmonary disease (COPD), decompensated cor pulmonale, neuromuscular diseases, acute respiratory failure (requiring continuous mechanical ventilation), and severe acidosis (defined as $\mathrm{pH}<7.3$ ). Fifteen consecutive patients referred to our hospital for NMV were recruited to the study. The type of ventilator, diagnoses, anthropometric data, and lung function data are presented in table 1 . 
Table 1 Diagnoses, ventilation modes, anthropometric and lung function parameters of the investigated population

\begin{tabular}{lc}
\hline Scoliosis (n) & 11 \\
Post-TBC (n) & 4 \\
PCV (n) & 10 \\
VCV (n) & 5 \\
Female (n) & 2 \\
Male (n) & 13 \\
Height (cm) & $157.4(12.3)$ \\
Weight (kg) & $50.5(9.5)$ \\
Age (years) & $57.9(12.0)$ \\
VC (1) & $1.1(0.3)$ \\
VC (\% pred) & $41.5(8.4)$ \\
FEV 1 (l) & $0.8(0.2)$ \\
FEV $_{1}(\%$ pred) & $72.2(9.7)$
\end{tabular}

$\mathrm{VCV}=$ volume cycled ventilation; $\mathrm{PCV}=$ pressure cycled ventilator; post-TBC = post-tuberculosis sequelae; $\mathrm{VC}=$ vital capacity; $\mathrm{FEV}_{1}=$ forced expiratory volume in one second.

Values are mean (SD).

MEASUREMENTS

Baseline measurements were performed prior to the run in period of NMV, the normal values for lung function data being those of the European Respiratory Society. ${ }^{7}$ Vital capacity (VC), forced expiratory volume in one second $\left(\mathrm{FEV}_{1}\right)$, and total lung capacity (TLC) were measured using a whole body plethysmography (Masterlap, Jäger, Würzburg, Germany). Resting daytime arterial capillary blood gas tensions were measured from the hyperaemic ear lobe whilst breathing room air. The measurements were taken during spontaneous breathing between 08.00 and 10.00 hours. After adaptation, blood gas tensions were assessed breathing room air during NMV. During sleep, transcutaneous measurements of oxygen saturation $\left(\mathrm{SaO}_{2}\right)$ were made using a pulse oximeter (Pulsoxy 7, AVL, Bad Homburg, Germany). All signals were transferred from the analogue output via an analogue-to-digital converter. After the signals were digitalised they were processed by computer into software, analysed, and recorded.

Standard polysomnographic recordings were performed with an Edit-sleep (MAP, Martinsried, Germany) and the polygraphic recording with Poly-MESAM (MAP, Martinsried, Germany). Standard polysomnographic recordings consisted of two electroencephalographic (EEG) derivations (C4-A1 and C3-A2), electro-oculography (EOG), electromyography (EMG) of the submental and tibialis anterior muscles, and electrocardiography (ECG, modified V2 lead). Respiration was monitored using oronasal thermistors and thoracic and

Table 2 Ventilator settings and blood gas analysis during spontaneous breathing and during the adaptation period of NMV without oxygen

\begin{tabular}{lclcl}
\hline & $P C V$ & \multicolumn{3}{c}{$V C V$} \\
\hline IPAP $\left(\mathrm{cm} \mathrm{H}_{2} \mathrm{O}\right)$ & 18.2 & $(2.6)$ & - & \\
EPAP $\left(\mathrm{cm} \mathrm{H}_{2} \mathrm{O}\right)$ & 2.3 & $(1.1)$ & - & \\
Inspiration $(\%)$ & 47.8 & $(4.2)$ & - & \\
$\mathrm{BF}(1 / \mathrm{min})$ & 20.1 & $(2.1)$ & - & \\
Tidal volume $(\mathrm{ml})$ & - & & 638.0 & $(32.7)$ \\
Inspiration $(\%)$ & - & & 46.0 & $(3.8)$ \\
$\mathrm{BF}(1 / \mathrm{min})$ & - & & $21.4(3.2)$ \\
$\mathrm{Flow}(1 / \mathrm{min})$ & - & & $50.8(6.6)$ \\
$\mathrm{Po}_{2}(\mathrm{kPa})$ & 10.7 & $(0.7)$ & $10.2(0.8)$ \\
$\mathrm{PCO}_{2}(\mathrm{kPa})$ & 5.1 & $(0.4)$ & $4.9(0.5)$ \\
$\mathrm{pH}$ & $7.42(0.04)$ & $7.41(0.04)$ \\
\hline
\end{tabular}

$\mathrm{VCV}=$ volume cycled ventilation; $\mathrm{PCV}=$ pressure cycled ventilator; IPAP = inspiratory positive airway pressure; EPAP = expiratory positive airway pressure; $\mathrm{BF}=$ breathing frequency. Values are mean (SD). abdominal movements with inductive plethysmography. Body position and oxygen saturation using finger pulse oximetry were also recorded. Sleep was hand scored in 30 second epochs according to the criteria of Rechtschaffen and Kales. ${ }^{8}$ We determined sleep efficiency as the total sleep time (TST) divided by the total time in bed (TIB). Sleep latency was defined as the time from the start of the study (lights off) to sleep onset. A transient desaturation was defined by a decrease in $\mathrm{SaO}_{2}$ of $4 \%$ or more lasting at least 10 seconds before returning to baseline. Awakenings (respiratory arousals) were defined as the combination of arousals associated with transient desaturations (compared to the preceding two minute period). Arousals were scored according to the American Sleep Disorders Association. ${ }^{9}$ The mean oxygen saturation $\left(\mathrm{mSaO}_{2}\right)$ and the lowest oxygen desaturation (nadir $\mathrm{SaO}_{2}$ ) in both REM and NREM sleep were determined. All patients were under direct video observation during the recordings.

\section{STUDY DESIGN}

In a prospective study design 15 consecutive patients with CRF due to thoracic restriction were recruited. To avoid "first night effect" at baseline, actual monitoring nights were preceded by one in-laboratory adaptation night with polygraphic recording equipment. Baseline polysomnographic in-laboratory recordings were obtained from all subjects before the initiation of NMV. The follow up polysomnographic in-laboratory recordings during spontaneous breathing (withdrawing NMV) were repeated six months (T6) and 12 months (T12-) after initiation NMV. At the 12 month investigation a second polysomnographic recording was performed with NMV (T12+).

All patients had a run in period of NMV of five days to determine the optimal ventilator settings. Initially all patients underwent volume cycled ventilation (VCV). If, after two days, patients felt uncomfortable with VCV, it was replaced by pressure cycled ventilation (PCV). Further details with respect to the adaptation to both VCV and PCV have been described elsewhere. ${ }^{10}$ For VCV, PLV 100 (Lifecare, Denver, Colorado, USA) and for PCV, Bilevel Positive Pressure Ventilation ("BiPAP-ST", Respironics Inc, Murrysville, Pennsylvania, USA) were used. The efficacy of NMV was established by a reduction in $\mathrm{PCO}_{2}$ to 4.7$5.7 \mathrm{kPa}$ during the five day adaptation period.

During the adaptation period patients were instructed in the use of the interface fit. All patients were initially ventilated via a conventional nose mask (Respironics, Murrysville, USA; and Res-care, Sydney, Australia). If pressure sores developed or if the quality of ventilation deteriorated due to leakage from the mask or the mouth, an individual nose or nosemouth mask was made by a dental laboratory. Blood gas tensions and pulmonary function were measured at baseline and at T6 and T12. All measurements were performed on room air. Patients' compliance with NMV was assessed by analysis of the ventilator time clock at T6 
Table 3 Blood gas tensions and lung function at baseline and after six (T6) and 12 months (T12) of non-invasive mechanical ventilation (NMV)

\begin{tabular}{|c|c|c|c|c|c|}
\hline \multirow[b]{3}{*}{$\mathrm{PO}_{2}(\mathrm{kPa})$} & \multicolumn{4}{|l|}{ Measurements } & \multirow{3}{*}{$\begin{array}{l}\text { ANOVA } \\
0.0001\end{array}$} \\
\hline & Baseline & T6 & \multicolumn{2}{|l|}{$T 12$} & \\
\hline & $6.8 \quad(1.3)$ & $9.0 \quad(1.1)$ & 8.9 & $(1.2)$ & \\
\hline $\mathrm{PCO}_{2}(\mathrm{kPa})$ & $7.6(0.9)$ & $6.0 \quad(0.5)$ & 6.0 & $(0.4)$ & 0.0001 \\
\hline $\mathrm{pH}$ & $7.37(0.04)$ & $7.40(0.02)$ & 7.39 & $(0.04)$ & 0.007 \\
\hline $\mathrm{HCO}_{3}^{-}(\mathrm{mmol} / \mathrm{l})$ & $32.1(6.3)$ & 27.0 & 25.9 & $(3.3)$ & 0.002 \\
\hline $\mathrm{VC}(1)$ & $1.1 \quad(0.3)$ & $1.2(0.3)$ & 1.2 & $(0.3)$ & 0.004 \\
\hline VC (\% pred) & $41.5 \quad(8.4)$ & $44.9 \quad(7.7)$ & 44.3 & $(6.7)$ & 0.02 \\
\hline $\mathrm{FEV}_{1}(1)$ & $0.8 \quad(0.2)$ & $0.8 \quad(0.2)$ & 0.9 & $(0.2)$ & 0.14 \\
\hline $\mathrm{FEV}_{1}(\%$ pred $)$ & $72.2(9.7)$ & $67.8 \quad(10.4)$ & 71.7 & $(10.4)$ & 0.02 \\
\hline $\operatorname{TLC}(1)$ & $2.9 \quad(0.7)$ & $3.0 \quad(0.6)$ & 3.1 & $(0.7)$ & 0.20 \\
\hline TLC (\% pred) & $60.8 \quad(14.9)$ & $64.9 \quad(13.4)$ & 63.7 & $(11.1)$ & 0.33 \\
\hline
\end{tabular}

$\mathrm{PO}_{2}, \mathrm{PCO}_{2}=$ arterial oxygen and carbon dioxide tensions $; \mathrm{HCO}_{3}^{-}=$bicarbonate $; \mathrm{VC}=$ vital capacity; $\mathrm{FEV}_{1}=$ forced expiratory volume in one second; TLC = total lung capacity.

Values are mean (SD).

Analysis of variance (ANOVA) for repeated measures was used as a global test ( $p<0.05$ was considered significant).

Table 4 Mean differences with 95\% confidence intervals (CI) of blood gases and lung function between T6 and baseline, T12 and T6

\begin{tabular}{|c|c|c|c|c|c|c|}
\hline \multirow[b]{3}{*}{$\mathrm{Po}_{2}(\mathrm{kPa})$} & \multicolumn{3}{|c|}{ Difference T6 - baseline } & \multicolumn{3}{|c|}{ Difference T12 - T6 } \\
\hline & \multicolumn{2}{|c|}{ Mean $(95 \%$ CI) } & \multirow{2}{*}{$\begin{array}{l}\text { Wilcoxon } \\
\star \star \star \star\end{array}$} & \multicolumn{2}{|c|}{ Mean $(95 \%$ CI) } & \multirow{2}{*}{$\begin{array}{l}\text { Wilcoxor } \\
\text { NS }\end{array}$} \\
\hline & $2.3 \quad(1.8$ & to 2.7 ) & & -0.2 & $(-0.4$ to 0.1$)$ & \\
\hline $\mathrm{PCO}_{2}(\mathrm{kPa})$ & $-1.5 \quad(-1.9$ & to -1.2 ) & 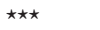 & -0.2 & $(-0.4$ to 0.0$)$ & $\star$ \\
\hline $\mathrm{pH}$ & $0.03(0.01$ & to 0.05 ) & $\star \star$ & $\begin{array}{r}-0.01 \\
0.02\end{array}$ & $(-0.02$ to & NS\# \\
\hline $\mathrm{HCO}_{3}^{-}(\mathrm{mmol} / \mathrm{l})$ & $-5.1)(-8.2$ & to -1.9$)$ & $\star \star \#$ & -1.0 & $(-2.6$ to 0.5$)$ & NS \\
\hline VC (1) & $0.09(0.03$ & to 0.12 ) & $\star \star \#$ & 0.01 & $(-0.02$ to 0.05$)$ & NS\# \\
\hline VC (\% pred $)$ & $3.3(1.3$ & to 5.3 ) & $\star$ & -0.5 & $(-2.8$ to 1.7$)$ & NS\# \\
\hline $\mathrm{FEV}_{1}(1)$ & $0.02(-0.04$ & to 0.08 ) & NS & 0.03 & $(-0.03$ to 0.10$)$ & NS \\
\hline $\mathrm{FEV}_{1}(\%$ pred $)$ & $-4.4 \quad(-8.0$ & to -0.8$)$ & NS\# & 3.9 & $(-0.2$ to 8.0$)$ & $\star$ \\
\hline TLC (1) & $0.15(-0.07$ & 7 to 0.40 ) & NS & 0.05 & $(-0.15$ to 0.24$)$ & NS \\
\hline TLC (\% pred) & $4.1)(-1.2$ & to 9.4$)$ & NS & -1.2 & $(-7.7$ to 5.3$)$ & NS \\
\hline
\end{tabular}

NS $=$ not significant; ${ }^{\star} \mathrm{p}<0.05 ;{ }^{\star \star} \mathrm{p}<0.01 ;{ }^{\star \star \star} \mathrm{p}<0.001 ; \#$ null hypothesis of normality rejected on a level of 0.10 .

For definition of abbreviations see table 3 .

Table 5 Sleep stages, mean and nadir oxygen saturation at baseline, after a single withdrawal night of NMV at 6 months (T6) and 12 months (T12-), and with NMV $(T 12+)$

\begin{tabular}{|c|c|c|c|c|c|}
\hline & \multicolumn{3}{|l|}{ Measurements } & \multirow[b]{2}{*}{ ANOVA } & \multirow[b]{2}{*}{$T 12+$} \\
\hline & Baseline & T6- & T12- & & \\
\hline Mean $\mathrm{SaO}_{2}$-NREM (\%) & $74.3(9.7)$ & $83.6(6.2)$ & $89.1(4.1)$ & 0.0001 & $92.7(2.11)$ \\
\hline Mean $\mathrm{SaO}_{2}$-REM (\%) & $63.8(9.8)$ & $72.6(6.2)$ & $77.9(4.1)$ & 0.0001 & $81.1(2.2)$ \\
\hline Nadir $\mathrm{SaO}_{2}$-NREM (\%) & $61.7(11.6)$ & $70.6(8.8)$ & $80.3(5.8)$ & 0.0001 & $87.0(2.9)$ \\
\hline Nadir $\mathrm{SaO}_{2}$-REM (\%) & $50.1(9.5)$ & $61.0(8.3)$ & $70.3(6.4)$ & 0.0001 & $79.5(5.1)$ \\
\hline Awakenings $(1 / \mathrm{h})$ & $29.4(20.1)$ & $19.4(15.5)$ & $12.4(11.6)$ & 0.0005 & $6.1(6.0)$ \\
\hline TST (min) & $219.3(52.0)$ & $275.3(60.0)$ & $276.6(43.3)$ & 0.0001 & $283.5(40.8)$ \\
\hline $\mathrm{SL}(\mathrm{min})$ & $29.0(17.5)$ & $30.1(18.7)$ & $35.6(23.1)$ & 0.30 & $26.1(13.5)$ \\
\hline SE (\%) & $64.1(11.0)$ & $73.4(10.8)$ & $73.5(8.5)$ & 0.002 & $81.3(7.9)$ \\
\hline REM (\% TST) & $5.2(4.2)$ & $8.5(6.3)$ & $10.4(5.0)$ & 0.004 & $14.6(6.0)$ \\
\hline REM-L (min) & $94.9(33.7)$ & $71.1(36.4)$ & $75.9(25.7)$ & 0.22 & $71.3(35.4)$ \\
\hline NREM $1 \& 2$ (\% TST) & $86.2(13.0)$ & $81.0(12.0)$ & $74.0(8.8)$ & 0.0002 & $67.1(8.3)$ \\
\hline NREM 3 \& 4 (\% TST) & $8.4(10.5)$ & $10.6(7.9)$ & $16.0(7.7)$ & 0.004 & $18.6(7.7)$ \\
\hline
\end{tabular}

Values are mean (SD).

Analysis of variance (ANOVA) for repeated measures was used as a global test ( $p<0.05$ was considered significant).

NREM = non-rapid eye movement sleep; REM = rapid eye movement sleep; REM-L = rapid eye movement sleep latency; $\mathrm{SaO}_{2}=$ oxygen saturation; $\mathrm{SL}$ = sleep latency; $\mathrm{SE}$ = sleep efficacy; TST $=$ total sleep time.

and T12, allowing calculation of the average daily rate of use.

ANALYSIS OF DATA

The results are expressed as mean (SD) or as the mean difference with $95 \%$ CI (absolute or in percentage of baseline). For the three measurements of blood gas tensions, lung function, and polysomnographic trials (baseline, T6, and T12-) analysis of variance (ANOVA) for repeated measurements was used as a global test (a $\mathrm{p}$ value of $<0.05$ was considered signifi- cant). The global test was followed by pairwise comparisons. Since the null hypothesis of normality is rejected for some differences (Shapiro-Wilk test, level 0.10) and the test of normality does not have much power (small sample size), the results of both parametric (95\% confidence interval for the mean value of differences) and non-parametric approaches ( $p$ value of Wilcoxon signed rank statistic) are given as sensitivity analysis.

\section{Results}

During the period of the study all consecutive patients referred with CRF were considered; six were ineligible due to exclusion criteria but 15 were enrolled, all of whom finished the study. In 10 patients PCV was prescribed and five patients were prescribed VCV. The ventilator settings and blood gas tensions during NMV after the adaptation period (without supplemental oxygen) are presented in table 2 . As evidenced by a reduction in $\mathrm{PCO}_{2}$ during $\mathrm{NMV}$, patients received efficient ventilatory support. No patient required oxygen therapy to maintain $\mathrm{PO}_{2}$ at $>8 \mathrm{kPa}$ and body weight did not change by more than $10 \%$ during the observation period.

Analysis of ventilator compliance revealed no differences between the rate of daily use at T6 and T12 (7.0 (1.4) and 6.9 (1.4) hours/day, respectively). There was therefore no correlation between compliance with NMV and the degree of improved sleep quality.

Before NMV all patients had CRF with daytime hypercapnia and hypoxaemia: $\mathrm{pH}$, vital capacity (VC) and forced expiratory volume in one second $\left(\mathrm{FEV}_{1}\right)$ were reduced and $\mathrm{HCO}_{3}$ was increased in comparison with published normal values (table 3). ${ }^{11}{ }^{12}$ Both at T6 and T12 the following parameters, measured during daytime spontaneous breathing, showed significant improvement compared with baseline values (tables 3 and 4): $\mathrm{PCO}_{2}$ and $\mathrm{HCO}_{3}$ decreased by $22.5 \%$ (95\% CI 26.0 to 18.9 ) and $17.4 \%$ (95\% CI 24.2 to 10.6 ), respectively; simultaneously $\mathrm{PO}_{2}$ increased by $34.0 \%$ (95\% CI 23.0 to 45.0 ), confirming the efficacy of the treatment. There was no relevant change in lung function.

In the pretreatment study significant nocturnal hypoventilation (nadir and $\mathrm{mSaO}_{2}$ ) was found in the whole group. When spontaneous breathing during sleep at baseline was compared with T6 and T12- a progressive improvement was found (tables 5 and 6, fig 1). Accordingly, from baseline to $\mathrm{T} 12-\mathrm{mSaO}_{2}$ increased significantly by $21.5 \%$ (95\% CI 12.4 to 30.6 ) and $24.9 \%$ (95\% CI 12.9 to 36.9 ) during NREM and REM sleep, respectively.

The lowest $\mathrm{mSaO}_{2}$ and nadir $\mathrm{SaO}_{2}$ occurred in REM sleep in both the baseline and follow up studies (T6 and T12-). The most efficient ventilation was found with NMV at T12+, as evidenced by the difference in $\mathrm{SaO}_{2}$ between T12+ and T12-(tables 5 and 6, fig 1).

Baseline sleep architecture was disrupted; the highest percentage of TST was spent in sleep stages NREM 1 and 2, the lowest amounts in REM and NREM stages 3 and 4 
Table 6 Mean differences with 95\% confidence intervals (CI) of sleep stages, mean and nadir oxygen saturation between T6 and baseline, T12 and T6, T12+ and T12-

\begin{tabular}{|c|c|c|c|c|c|c|}
\hline & \multicolumn{2}{|l|}{ Difference T6 - baseline } & \multicolumn{2}{|l|}{ Difference T12 - T6 } & \multicolumn{2}{|l|}{ Difference T12+ - T12- } \\
\hline & Mean $(95 \% C I)$ & Wilcoxon & Mean $(95 \% C I)$ & Wilcoxon & Mean $(95 \%$ CI) & Wilcoxon \\
\hline Mean $\mathrm{SaO}_{2}$-NREM (\%) & $9.3(5.6$ to 13.1$)$ & $\star \star \star$ & $5.3(3.1$ to 7.4$)$ & $\star \star \star$ & $3.9(2.4$ to 5.3$)$ & $\star \star \star$ \\
\hline Mean $\mathrm{SaO}_{2}$-REM (\%) & $8.8(5.1$ to 12.6$)$ & $\star \star \star$ & $5.3(3.0$ to 7.6$)$ & $\star \star \star$ & $3.3(1.8$ to 4.7$)$ & $\star \star \star$ \\
\hline Nadir $\mathrm{SaO}_{2}$-NREM (\%) & 8.9 (3.5 to 14.3$)$ & $\star \star \star$ & $9.7(5.0$ to 14.3$)$ & $\star \star$ & $6.7(4.0$ to 9.5$)$ & $\star \star \star \star$ \\
\hline Nadir $\mathrm{SaO}_{2}-\mathrm{REM}(\%)$ & $10.9(5.7$ to 16.1$)$ & $\star \star \star$ & $9.3(5.8$ to 12.7$)$ & $\star \star \star$ & $9.3(4.8$ to 13.7$)$ & $\star \star$ \\
\hline Awakenings $(1 / \mathrm{h})$ & $-10.0(-15.1$ to -4.9$)$ & $\star \star \star \# \#$ & $-7.1(-14.4$ to 0.2$)$ & $\star \star \#$ & $-6.3(-10.7$ to -1.8$)$ & $\star \star \#$ \\
\hline $\mathrm{TST}(\mathrm{min})$ & $38.0(22.1$ to 53.9$)$ & $\star \star \star$ & $10.2(-10.9$ to 31.6$)$ & NS & $15.9(7.6$ to 24.3$)$ & $\star \star$ \\
\hline $\mathrm{SL}(\min )$ & $1.1(-7.3$ to 9.6$)$ & NS & $5.5(-1.2$ to 12.1$)$ & NS & $-9.3(-17.9$ to -1.0$)$ & * \\
\hline SE $(\%)$ & $9.4(5.0$ to 13.7$)$ & $\star \star$ & $0.1(-5.7$ to 5.9$)$ & NS & $7.8(4.6$ to 11.0$)$ & $\star \star \star \star$ \\
\hline REM (\% TST) & $3.3(-0.1$ to 6.7$)$ & $\star \#$ & $1.9(-0.1$ to 3.9$)$ & NS & $3.9(2.0$ to 5.8$)$ & $\star \star \#$ \\
\hline REM-L (min) & $-22.3(-59.6$ to 15.0$)$ & NS & $5.1(-8.4$ to 18.6$)$ & NS & $-4.6(-19.8$ to 10.6$)$ & NS\# \\
\hline NREM $1 \& 2(\%$ TST) & $-5.2(-10.8$ to 0.3$)$ & $\star$ & $-7.1(-11.3$ to -2.8$)$ & $\star \star \star$ & $-6.9(-10.9$ to -2.8$)$ & $\star \star \star \#$ \\
\hline NREM $3 \& 4$ (\% TST) & $2.2(-2.0$ to 6.4$)$ & NS & $5.4(1.1$ to 9.7$)$ & $\star \star$ & $2.6(-0.7$ to 6.0$)$ & NS \\
\hline
\end{tabular}

NS $=$ not significant; ${ }^{\star} \mathrm{p}<0.05 ;{ }^{\star \star} \mathrm{p}<0.01 ;{ }^{\star \star \star} \mathrm{p}<0.001 ;$ \#null hypothesis of normality rejected on a level of 0.10

For definition of abbreviations see table 5 .

sleep, and the greatest number of awakenings were found (tables 5 and 6, fig 2). Also, the lowest TST and sleep efficiency were measured.

In both $\mathrm{T} 6$ and $\mathrm{T} 12-$ sleep quality progressively improved (tables 5 and 6, fig 2). Thus, TST and sleep efficiency increased by $26.8 \%$ (95\% CI 11.6 to 42.0$)$ and $17.5 \%$ (95\% CI 5.4 to 29.6), respectively, and awakenings decreased by $54.0 \%$ (95\% CI 70.3 to 37.7$)$. Accordingly, REM and NREM sleep stages 3

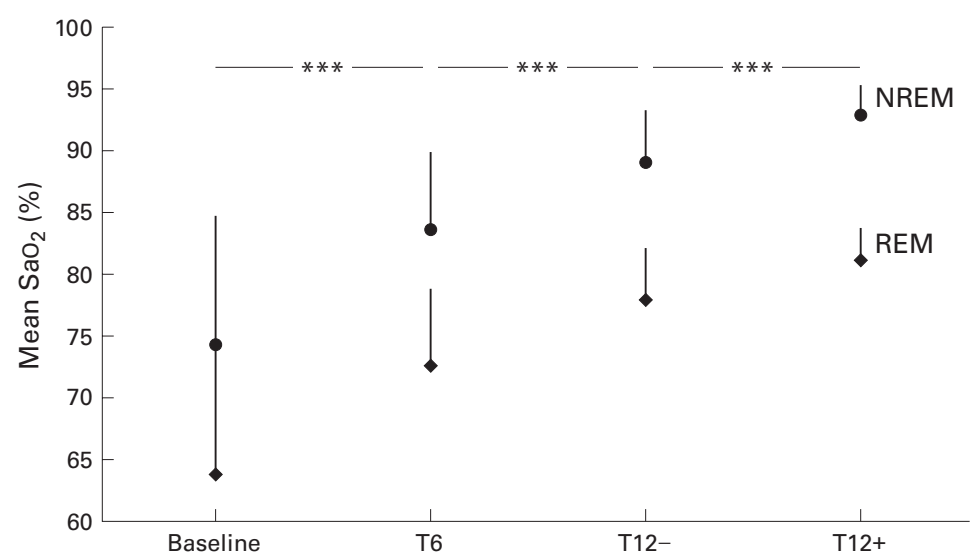

Figure 1 Mean (SD) oxygen saturation ( $\mathrm{SaO}_{2}$ ) at baseline, after a single withdrawal night of NMV at 6 months (T6) and 12 months (T12-), and with NMV (T12+) in rapid eye movement (REM) and non-rapid eye movement (NREM) sleep. The comparisons were performed in pairs with the Wilcoxon test; ${ }^{\star \star \star} p<0.001$.

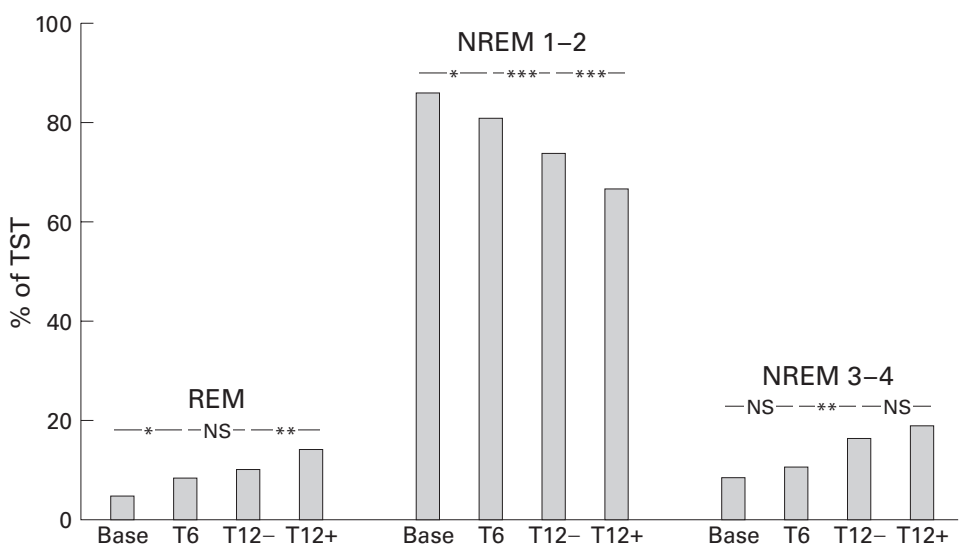

Figure 2 Percentage of total sleep time (TST) during rapid eye movement (REM) sleep, non-rapid eye movement (NREM) sleep stages 1-2 and stages 3-4 at baseline, after a single withdrawal night of NMV at 6 months (T6) and 12 months (T12-), and with NMV (T12+). The comparisons were performed in pairs with the Wilcoxon test; $N S=$ not significant, ${ }^{\star} p<0.05,{ }^{\star} p<0.01$. and 4 significantly increased. However, the most significant improvements in both nocturnal ventilation and sleep quality were seen during NMV at 12 months (T12+) (table 6).

\section{Discussion}

The main findings of this study were that both spontaneous nocturnal ventilation and sleep quality progressively improved with NMV in patients with thoracic restriction, measured by withdrawing NMV for one night at six (T6) and 12 months (T12-) after initiation of NMV. However, a mild degree of hypoventilation remained apparent during the withdrawal studies, especially during REM sleep. Along with ventilation, the greatest improvement in sleep quality was achieved during the intervention itself $(\mathrm{T} 12+)$. To the best of our knowledge this is the first study to investigate spontaneous breathing and sleep quality after long term NMV, performing repeated measurements in patients with $\mathrm{CRF}$ due to thoracic restriction.

The study does, however, have several limitations. Firstly, the absence of a control group is a significant limitation but, because of ethical considerations, a control group without NMV was not considered acceptable. Furthermore, such a design would require the enrolment of a large number of patients to ensure equal distribution and such a study would probably not be realistic for a single institution.

Secondly, no neuropsychological measurements were performed in this study. In particular, quality of life and vigilance were not investigated. Due to the physiological character of the study we focused exclusively on the given parameters. However, using different questionnaires in heterogeneous populations it has recently been shown that NMV leads to an improvement in the quality of life. ${ }^{6}{ }^{13-15}$

Thirdly, no direct parameter of nocturnal ventilation such as transcutaneous $\mathrm{CO}_{2}$ $\left(\mathrm{PtcCO}_{2}\right)$ was measured. Previous studies of patients with chest wall disorders have shown that the decrease in $\mathrm{SaO}_{2}$ and increase in $\mathrm{PtcCO}_{2}$ associated with hypoventilation are inextricably linked. ${ }^{1016}{ }^{17}$ In our study population the documented nocturnal decrease in $\mathrm{SaO}_{2}$ is therefore sufficient evidence of hypoventilation during 
sleep; conversely, the increase in nocturnal $\mathrm{SaO}_{2}$ represents an improvement in ventilation.

Finally, one could question whether, during the four sleep studies, a gradual acclimatisation to the sleep laboratory may have affected the sleep quality. However, in order to avoid a "first night effect" the study was designed to include an in-laboratory adaptation night with a polygraphic recording before the baseline full polysomnography. The mean and nadir oxygen saturation of these studies did not show any statistical difference. It therefore seems unlikely that adaptation phenomena influenced the results.

In this study the most significant improvement in ventilation and sleep quality was achieved during NMV. However, during NMV, periods of hypoventilation still occurred. The main cause of these hypopnoeas during NMV, as has been previously shown, were episodes of mouth leakage. ${ }^{18}$ Other factors may be responsible for hypopnoeas during NMV-for example, it has recently been shown that volume cycled ventilation in control mode may induce reduction of effective ventilation by glottic closure. ${ }^{19}{ }^{20}$ However, it was not the aim of this study to investigate the relevance of mouth leakage and glottis closure on ventilation and sleep quality. Although it was not an end point of this study to compare effectiveness or comfort of the two different ventilation modes being used, it was noted that two thirds of the population preferred PCV. The blood gas tensions during NMV and daytime revealed no differences between the two groups.

Previous withdrawal studies have also investigated the effect of NMV on sleep and nocturnal breathing in patients with CRF after initiation of NMV. Piper and Sullivan ${ }^{17}$ investigated 14 patients with CRF due to neuromuscular and chest wall disorders after NMV for at least six months. It was found that, after a single night of withdrawal from NMV, spontaneous breathing during sleep, although still abnormal, had markedly improved. The most significant hypoventilation was apparent during REM sleep. Goldstein et $a l^{16}$ investigated three patients after eight weeks of treatment with negative pressure ventilation and found that, as judged by $\mathrm{SaO}_{2}$ and $\mathrm{CO}_{2}$, spontaneous ventilation during a withdrawal trial was better than the pretreatment values but worse than those recorded during NMV.

Although not investigated in this study, it would not be expected that a one night withdrawal of NMV would induce a relevant deterioration in clinical condition, heart function, and daytime ventilation. We therefore postulate a carry over effect from the long term NMV into the withdrawal night, despite the deterioration in both nocturnal ventilation and sleep quality in the studies at T6 and T12-. Neither the study design nor the findings aim to suggest discontinuing $\mathrm{NMV}$, apart from for scientific investigations.

Longer periods of withdrawal of NMV have been shown to induce clinical deterioration in other studies. ${ }^{21-23}$ Gas exchange deteriorated and daytime symptoms recurred after a two week withdrawal of negative pressure ventila- tion in a patient who had been using NMV for 12 months. $^{21}$ Two further studies involving withdrawal of positive pressure ventilation for 7-15 days also found deterioration of sleep quality, clinical condition, and/or gas exchange. $^{22} 23$

The findings of improved sleep quality and ventilation during NMV in this study are in line with previous studies. In patients with COPD an improvement in sleep quality and nocturnal ventilation was found after three months of NMV. ${ }^{14}$ In patients with neuromuscular diseases long term NMV improved both nocturnal ventilation and sleep quality, ${ }^{24}{ }^{25}$ and in patients with chest wall diseases without established CRF during the daytime (but mild nocturnal hypoventilation) NMV improved nocturnal ventilation but not sleep quality after 15 days of NMV. ${ }^{13}$

The rationale for the progressive improvement in spontaneous nocturnal ventilation and sleep quality during the one year observation period remains speculative. There may be several explanations for these findings-for example, increased adaptation to the NMV and interface or slowly improving neurophysiological phenomena. It was not the aim of this study to favour one of the two main hypotheses of how NMV works (respiratory muscle rest and/or resetting the chemosensitivity). ${ }^{26}{ }^{27} \mathrm{We}$ acknowledge that these data are not provided by this present study and hence the mechanism by which improvement occurs remains unknown.

Two specific issues that arise from the results of this study should be discussed. It is generally agreed that spontaneous ventilation is worst during sleep in CRF. ${ }^{161722} 23$ This may result partly from lung mechanics in the supine position, ${ }^{27}$ pathological breathing pattern, ${ }^{28}$ and reduced chemosensitivity during REM sleep. ${ }^{16}$ However, the diaphragm is essential for ventilation in REM sleep ${ }^{28}$ since in REM sleep a marked reduction in intercostal muscle activity is found. ${ }^{29}$ During NREM sleep there is an increased contribution of the rib cage to breathing $^{30}$ so it may be postulated that a progressive improvement in inspiratory muscle function is the main cause of increased ventilation during both REM and NREM sleep.

Other studies of patients with neuromuscular diseases or chest wall disorders have concluded that the correction of sleep disordered breathing and the associated arousal responses are the main mechanisms for the beneficial effects of NMV. ${ }^{17}{ }^{25}$ However, in a previous study we found that daytime NMV in awake patients with CRF also leads to an improvement in both spontaneous daytime and nocturnal ventilation without direct treatment of the associated sleep disordered breathing itself. $^{31}$

These findings imply that improvement obtained with daytime NMV is not directly mediated by an effect on sleep quality, and suggest that NMV does not exclusively need to be directed at what is functionally the worst period of hypoventilation. CRF may therefore be at least partially reversed without primarily preventing sleep disordered breathing. 
We conclude from the results of this study that single night withdrawal of NMV six and 12 months after initiation of nocturnal NMV produces both spontaneous ventilation during sleep and progressive improvement in sleep quality compared with baseline in patients with CRF due to thoracic restriction. However, the greatest improvements in quality of nocturnal ventilation and sleep were still achieved during nocturnal NMV.

The authors thank M Polkey and P Turkington for their critical remarks and linguistic advice and Chr Henrich-Eberl for her statistical advice. We are grateful to K Krause for the excellent technical assistance in the sleep laboratory and A Simon for analysis of the polysomnographic trials.

1 McNicholas WT. Impact of sleep in respiratory failure. Eur Respir 7 1997;10:920-33.

2 Carroll N, Branthwaite MA. Control of nocturnal hypoventilation by nasal intermittent positive pressure ventilation. 1988;43:349-53.

3 Ellis RE, Bye PT, Bruderer JW, et al. Treatment of respiratory failure during sleep in patients with neuromusc ular disease. Positive-pressure ventilation through a nose mask. Am Rev Respir Dis 1987;135:148-52.

4 Gay PC, Patel AM, Viggiano RW, et al. Nocturnal nasal ventilation for treatment of patients with hypercapneic respiratory failure. Mayo Clin Proc 1991;66:695-703.

5 Leger P, Bedicam JM, Cornette A, et al. Nasal intermittent positive pressure ventilation. Chest 1994;105:100-5.

6 Simonds AK, Elliott MW. Outcome of domiciliary nasal intermittent positive pressure ventilation in restrictive and obstructive disorders. Thorax 1995;50:604-9.

7 Quanjer PH, Dalhuijsen A, Van Zomeren BC. Summary equations of reference values. Bull Eur Physiopathol Respi 1983;19(Suppl 5):45-51.

8 Rechtschaffen A, Kales A, eds. A manual of standardized terminology, techniques and scoring system for sleep stages of human subjects. US Department of Health, Education and Welfare, NIH Publication No. 204, 1968: 1-64.

9 American Sleep Disorders Association. EEG arousals: scorAmerican Sleep Disorders Association. EEG ar

10 Schönhofer B, Sonneborn M, Haidl P, et al. Comparison of two controlled modes for non-invasive mechanical ventilation: volumetric respirator versus barometric device with two levels of positive airway pressure. Eur Respir $\mathcal{F}$ 1997;10:184-91.

11 American Thoracic Society. Lung function testing: selection of reference values and interpretative strategies. Am Rev Respir Dis 1991;144:1202-18.

12 Cerveri I, Zoia MC, Fanfulla F, et al. Reference values of arterial oxygen tension in the middle-aged and elderly. Am $\mathcal{7}$ Respir Crit Care Med 1995;152:934-41.

13 Masa JF, Celli BR, Riesco JA, et al. Noninvasive positive pressure ventilation and not oxygen may prevent overt ven- tilatory failure in patients with chest wall diseases. Chest 1997;112:207-13

14 Meecham Jones DJ, Paul EA, Jones PW, et al. Nasal pressure support ventilation plus oxygen compared with oxygen therapy alone in hypercapnic COPD. Am F Respir Crit Care Med 1995;152:538-44.

15 Pehrsson K, Olofson J, Larsson S, et al. Quality of life of patients treated by home mechanical ventilation due to restrictive ventilatory disorders. Respir Med 1994;88:21-6.

16 Goldstein RS, Molotiu N, Sktrastins R, et al. Reversal of sleep-induced hypoventilation and chronic respiratory failure by nocturnal negative pressure ventilation in patients with restrictive ventilatory impairment. Am Rev Respir Dis 1987; 135:1049-55.

17 Piper AJ, Sullivan CE. Effects of long-term nocturnal nasal ventilation on spontaneous breathing during sleep in neuromuscular and chest wall disorders. Eur Respir f 1996; 9:1515-22.

18 Bach JR, Robert D, Leger P, et al. Sleep fragmentation in kyphoscoliotic individuals with alveolar hypoventilation treated by NIPPV. Chest 1995;107:1552-8.

19 Jounieaux V, Aubert G, Dury M, et al. Effects of nasal positive-pressure hyperventilation on the glottis in normal awake subjects. F Appl Physiol 1995;79:176-85.

20 Parreira VF, Jounieaux V, Aubert G, et al. Nasal two-level positive-pressure ventilation in normal subjects. $A m \mathcal{F}$ positive-pressure ventilation in normal

21 Garay SM, Turino GM, Goldring RM. Sustained reversal of chronic hypercapnia in patients with alveolar hypoventilation syndromes: long-term maintenace with noninvasive mechnical ventilation. Am f Med 1981;70:269-74

22 Hill NS, Eveloff SE, Carlisle CC, et al. Efficacy of nocturnal nasal ventilation in patients with restrictive thoracic disease. Am Rev Respir Dis 1992;145:365-71.

23 Jimenez JFM, Sanchez de Cos Escuin J, Vicente CD, et al. Nasal intermittent positive pressure ventilation. Chest 1995;107:382-8.

24 Annane D, Quera-Salva MA, Lofaso F, et al. Mechanisms underlying effects of nocturnal ventilation on daytime blood gases in neuromuscular diseases. Eur Respir 7 1999;13:157-62.

25 Barbé F, Quera-Salva MA, De Lattre J, et al. Long-term effects of nasal intermittent positive-pressure ventilation on pulmonary function and sleep architecture in patients with neuromuscular diseases. Chest 1996;110:1179-83.

26 Hill NS. Noninvasive ventilation. Am Rev Respir Dis 1993; 147: $1050-5$.

27 Bergofsky EH. Respiratory failure in disorders of the thoracic cage. Am Rev Respir Dis 1979;119:643-69.

28 Stradling JR, Warley ARH. Bilateral diaphragmatic paralysis and sleep apnoea without diurnal respiratory failure. Thorax 1988;43:75-7.

29 Tusiewicz K, Moldofsky H, Bryan AC, et al. Mechanics of ribcage and diaphragm during sleep. $\mathcal{F}$ Appl Physiol: Respir Environ Exerc Physiol 1977; 3 :600-2.

30 Tabachnik E, Muller NL, Bryan AC, et al. Changes in ventilation and chest wall mechanics during sleep in normal adolescents. F Appl Physiol 1981;51:557-64.

31 Schönhofer B, Geibel M, Sonneborn M, et al. Daytime mechanical ventilation in chronic respiratory insufficieny. Eur Respir f 1997;10:2840-6. 